\title{
Themed Section Editorial
}

$>\quad$ Deirdre Byrne.

University of South Africa, Pretoria, South Africa.

byrnedc@unisa.ac.za (ORCID: https://orcid.org/0000-0002-4436-6632)

\section{$>\quad$ Chantelle Gray}

North-West University, Potchefstroom, South Africa

gray.chantelle@gmail.com (ORCID: https://orcid.org/0000-0003-1061-4463)

Published by

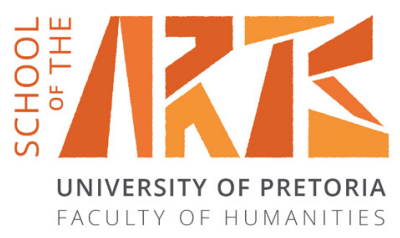

Introduction
The diversity of the articles included in this special issue attests to the ongoing relevance of gender as a crucial determinant of individual and social identity, a key component of political engagement, and a multidimensional field of scholarship. Gender is also a core aspect of dis/positionality, by which we mean the intersections of gender, race, class, human and physical geographies, and any other aspects of identities that are 'markers of relational positions rather than essential qualities' (Maher \& Tetreault 1993:118; see also Alcoff 1988; Benard 2016; Darling-Wolf 1998). By emphasising gender as productive, plural and constitutive of the dis/positionality of a subject, rather than a quintessential, intrinsic and static constituent of the subject per se, these articles aim to dispel the notion that subjectivity is 'universal', and that gender is in any sense binary.

Over the past century, postcolonial and decolonial scholars have queried the relevance of notions of feminism from the global north for the global south. The assumption underpinning this challenge is that geographical location and cultural context exert a powerful influence on what kinds of theory can be seen as valid, thus adding an intersectional component to analyses from a feminist or gender studies angle. This debate adds another dimension to dis/positionality, namely visibility, which manifests as legitimacy and authority - hence social and political power - in subject-formation, or, conversely, invisibility/invisibilisation - a marginalising and silencing tactic. These, moreover, are tied to the construction and expression of meaning. Accordingly, the body, which is gendered, racialised and intersectionally othered, can be said to form a material locus within systems of signification and on which these systems of signification are inscribed.

One such system of signification is culture and cultural assimilation through colonisation. Gender scholars in the late twentieth and early twenty-first centuries have

Introduction

Dis/Positions: Reflections on Gender, Sexuality, Race and Culture 
attained a new appreciation of the necessity to take what is broadly known as 'culture' into account when pursuing their research. Here, culture is understood in its widest possible sense: as 'a social domain that emphasises the practices, discourses and material expressions, which, over time, express the continuities and discontinuities of social meaning of a life held in common' (James et al. 2015:53). This contemporary definition's focus on continuities and discontinuities - that is, on historical, contextual, socio-political and cultural specificities - is a salutary reminder that gendered practices seldom conform to coherent and normative categories and policies, even when these are enforced. Adding culture into our understanding of dis/positionality requires careful thought about what we mean by otherness, diversity and human rights. This is one of the most important developments in the theory and practice of feminism, women's and gender studies, and critical race studies in the past century, and will probably endure as a nodal point of development of the discipline for several years to come.

Directly related to the centrality of culture is the process of knowledge production. Feminists and gender scholars have, at least since Donna Haraway's 1988 article on situated knowledges, been acutely aware of the idea that the "knowing self is partial in all its guises, never finished, whole, simply there and original' (Haraway 1988:586). In other words, knowledge is 'always constructed and stitched together imperfectly, and therefore able to join with another, to see together without claiming to be another' (Haraway 1988:586). But this understanding did not immediately lead to a broader consideration of northern epistemological dominance. It has only been the recent and widespread development of decolonial theory and praxis that have given us pause. Knowledge and knowledge production should thus be viewed as contested/contesting spaces with multi-layered and intersecting aspects that continue to be in need of new practices. For this reason, we have chosen to include articles in this special issue that offer insights into the ongoing dialogues and provocations about sex, gender, race and identity - as constituents of dis/positionality - in both the global south and the global north. The articles are aimed at disrupting structural and essentialist notions of sex, gender, race and dis/positionality, as well as the structures of power, meaning and value that inform and sustain these. It is our hope that this special issue will enable readers to move towards deeper understandings of sexuality and gendered identities, the structures of power that produce and reproduce normativity, and the myriad resistances to these enforced dis/positions. This, we believe, will create a platform from which more nuanced discussions around gendered desire and sexuality, and its intersections with race and dis/positionality, may come into view. The aim of this special issue, then, is to begin envisioning identity arrangements that are different, more equal and more empowering of those who are currently seen as 'other' and inferior on the grounds of race, gender, sexual identity, geography, cultural origin, or any other arbitrary, but well-established, value system. 
In the first six articles, the authors address various cultural representations of gendered dis/positionalities. Kelly Gardiner's opening article, 'Tomboys: Performing gender in popular fiction', explores the prevalence and success of fictional tomboys in young adult fiction, arguing that the tomboy subject-position offers positive role models for adolescent girl readers who may feel dissatisfied with the restrictive gender norms that are prescribed for them by society. Gardiner postulates that through the imaginative experience of reading such works, adolescent girls can explore a wider range of options for their own lived experience of gender than is offered to them by consensus society, while - in most cases - returning to the fold of heterosexual subjectivity as soon as they reach adulthood. The second article, by Chantelle Gray, titled 'The spectre-image: A hauntology of Skoonheid and Kanarie', turns to cinema and holds that a Deleuzian understanding of cinematography in combination with Derrida's notion of hauntology can shed light on some of the repressed, but insistent, aspects of race and gender in the South African imaginary. She deploys hauntology to interrogate and trace the ghosts of heteronormative whiteness - and thus the spectres of queerness and blackness arguing that the gendered foregrounding in two recent motion pictures dealing with white Afrikaner homosexuality, namely the 2011 film, Skoonheid (Beauty) and the 2018 film, Kanarie (Canary), effectuates racial erasure. This is followed by Elbie van den Berg's article, 'Female impersonation and gender ambivalence: Does drag challenge gender norms?', in which Van den Berg explores the paradoxical tension between reconfirming and challenging gendered practices through drag performance. With a focus on the televised drag race shows of RuPaul, following Judith Butler, she argues that although drag has subversive potential, it does not necessarily challenge compulsory heterosexuality. Nevertheless, drag performance is a symbolic inversion of hegemonic gender norms, and a blurring of and playing with gender boundaries.

Turning to art, Adéle Adendorff's article, 'All that glitters is not gold: counter-penetrating in the name of Blackness and queerness, or, Athi-Patra Ruga's camp act in the dirt', fleshes out the complexities that arise from the intersection of the terms 'Black' and 'queer'. Looking at the work of South African artist, Athi-Patra Ruga, she draws on diverse historical, social and textual resources to interpret Ruga's dismantling of dominant post-apartheid and postcolonial narratives vis-à-vis a close reading of some of his provocative avatars and his method of 'counter-penetration'. The latter, she argues, is a subversive and transgressive act intent on contaminating and infecting conventional narratives of history, identity and politics. Still focusing on art, but now turning to photographs of Vietnamese brides in their home environments by Oh SoonHwa, is Wernmei Yong Ade's article, " QQuiet Dream": Vietnamese women and marriage migration'. In the article, Ade teases out the poignant contradiction between geospatial and socio-economic dis/positions for Vietnamese women, who are pressured into marriages with foreigners whom they have never met. Having covered literature, 
cinema, television, performance art and photography, the issue turns to contemporary uses of Rosie the Riveter. In her article, 'The return of Rosie the Riveter: contemporary popular reappropriations of the iconic World War Two poster image', Belinda du Plooy attests to the power of signification to create understandings of femininity as strength in diverse contexts through reappropriation - not as cultural appropriation, but as cultural reinvention.

The seventh article, by Kudzaiishe Vanyoro, marks the last on cultural representations of gendered dis/positionalities while simultaneously shifting the focus to a more sociological lens and thus forms the bridge between the first group of articles and the second, the latter of which pays attention to the dynamic interplay between gender, society, culture and politics. In his article, titled 'An analysis of the intersections between race and class in representations of Black and white gay men in QueerLife', Vanyoro uses Critical Diversity Literacy (CDL) to read the underlying meaning in texts and images. The author concludes that QueerLife is complicit in the construction of gay identity categories that seek to appeal to urban, white, middle-class gay-identifying communities in South Africa. This is followed by Bianca Parry's article, 'Eating burnt toast: the lived experiences of female breadwinners in South Africa'. Parry unpacks, through ethnographic research, the complex determinants of women's experience of being sole breadwinners in families and reveals their necessary diversity and the dis/positionality of their subjective experiences. The final article by Fikile Vilikazi and Gabisile Mkhize, titled 'Rethinking gender and conduits of control: a feminist review', looks at genderbased violence in South Africa. They argue that even though the South African Constitution has been hailed as one of the most progressive in the world and has received high acclaim internationally, the 'war on women', their bodies and their right to self-determination persists, often enabled by culturally sanctioned norms and behaviour patterns.

As a final point, this special issue would like to see realised the same hope that undergirds the UN's fifth Sustainable Development Goal: achieve gender equality and empower all women and girls. The authors and editors understand 'gender equality' to refer to equality of access to resources and the rights to self-actualisation which, we hold, need to be extended to people of all gender and sexual identities. But, as we stated earlier, gender is only one aspect of dis/positionality and should be examined in its intersections with race, geography, colonialism, and so forth. It may perhaps be said that we share the utopian wish for gender arrangements to be different, more equal and more empowering of those who are currently seen as 'other' and inferior on the grounds of race, gender, gender identity, geographical or cultural origin, and any other intersecting facets. However, this utopia is not an unattainable, mythical place, but one which we believe is created every time we prefigure new subjectivities. 


\section{REFERENCES}

Alcoff, LM. 1988. Visible identities: Race, gender, and the self. Oxford: Oxford University Press.

Benard, A. 2016. Colonizing black female bodies within patriarchal capitalism: Feminist and human rights perspectives. Sexualization, Media, \& Society OctoberDecember:1-11.

Darling-Wolf, F. 2004. On the possibility of communicating: Feminism and social position. Journal of Communication Enquiry 28(1):29-46.

Haraway, D. 1988. Situated knowledges: The science question in Feminism and the privilege of partial perspective. Feminist Studies 14(3):575-599.

James, P, Magee, L, Scerri, A \& Steger, MB. 2015. Urban sustainability in theory and practice: Circles of sustainability. London: Routledge.

Maher, FA \& Tetreault, MK. 1993. Frames of positionality: Constructing meaningful dialogues about gender and race. Anthropological Quarterly 66(3):118-126. 